\title{
Short stature in severe paediatric heart failure: The deleterious role of growth hormone replacement
}

\author{
Reiner Buchhorn* \\ Department of Paediatrics, Caritas Krankenhaus Bad Mergentheim, Uhlandstraße 7, 97980 Bad Mergentheim, Germany
}

\section{Introduction}

Growth failure secondary to heart failure in childhood is well documented, but not well understood. A current analysis of 640 children from Chile who require cardiac surgery for congenital heart defects showed short stature in $24.1 \%$ [1]. The highest percentage of short stature are related to heart failure of cause complete atrioventricular canal (66.7\%), ventricular septal defect (33\%) and after Norwood 1 repair of the hyperplastic left heart syndrome (33.3\%). Low serum insulin-like growth factor - 1 level (IGF-1) indicates heart failure in children with left to right shunt due to congenital heart defects [1] that increase after corrective surgery [3,4]. Impaired linear growth in infants with single ventricle physiology seems to be an indicator of worse neurodevelopmental outcome [5].

McElhinney et al. [6] proposed recombinant growth hormone treatment in children with short stature of cause heart failure due dilated cardiomyopathy published in PEDIATRICS in 2004. In a so called prospective, single center, randomized, partially blinded, crossover trial only 8 of an intended 15 patients were enrolled. Two of the eight patients developed progressive heart failure and underwent cardiac transplantation. However, the authors conclude that "the benefits of growth hormone treatment were not associated with significant attributable side effects...". Growth hormone therapy was associated with significant acceleration of somatic growth.

We report a boy who suffer from heart failure nearly his whole childhood up to his heart transplantation at the age 12 years after 6 cardiac surgeries in early life. He received growth hormone treatment at the age of 10 years, after pediatric endocrinologists had proposed a final height of $130 \mathrm{~cm}$. We can clearly demonstrate that his final cardiac decompensation was caused by growth hormone treatment.

\section{Case report}

At the first presentation with an age of 3 years the boy had balloon valvuloplasty of pulmonary stenosis in infancy, atrial septal defect closure and patch augmentation of the right ventricular outflow tract. We found heart failure of cause a significant mitral valve regurgitation. After three attempts for mitral valve reconstruction he received mitral valve replacement at the age of 4 years. Further he received a dual chamber and later biventricular pacemaker of cause a complete postoperative atrioventricular block. However, he remained in heart failure due to left ventricular dysfunction with high NT pro Brain Natriuretic Peptide values as shown in figure 1. We added metoprolol to captopril/digoxin treatment for clinical stabilization and reach a drop down of the highly activated renin angiotensin system (renin $12170 \mathrm{ng} / \mathrm{l}$ to $1736 \mathrm{ng} / \mathrm{l}$; normal range $10.6-66.9 \mathrm{ng} / \mathrm{l}$ ) at the age of 5 years.

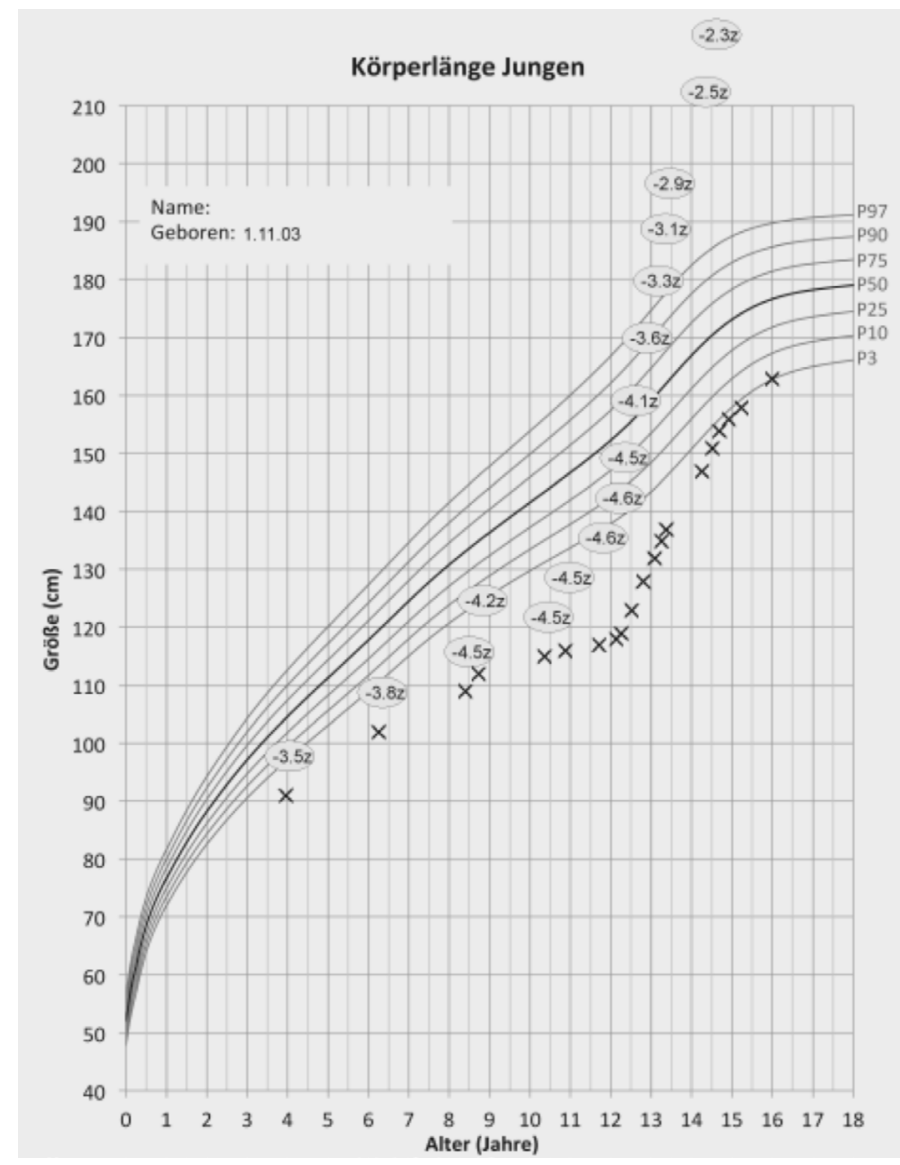

Figure 1. Original growth chart of a boy with chronic heart failure due to mitral valve insufficiency and dilated cardiomyopathy after mitral valve replacement at the age 4 years. Cardiac decompensation after starting growth hormone therapy for short stature at the age of 11 years leading to heart transplantation at the age of 12 years. Catch up growth without any growth promoting therapy.

${ }^{\star}$ Correspondence to: Reiner Buchhorn, Department of Paediatrics, Caritas Krankenhaus Bad Mergentheim, Uhlandstraße 7, 97980 Bad Mergentheim, Germany, Tel: +49 7931 58-2301; Fax: +49 7931 58-2390; E-mail: reiner. buchhorn@ckbm.de

Received: November 26, 2019; Accepted: December 13, 2019; Published: December 16, 2019 
The boy developed short stature due to growth hormone deficiency as indicated in three growth hormone stimulation tests. We decide against growth hormone replacement of cause concerns about safety in adults with heart failure, who were treated with growth hormone in prospective trials [7]. However, based upon the small study published in PEDIATRICS [6] and a proposed final height of $130 \mathrm{~cm}$ the boy received a low dose of $0.2 \mathrm{mg}$ recombinant growth hormone. Together with increasing IGF-1 serum concentration the NT-BNP increase to very high values (Figure 2 ) and the volume monitoring by the pacemaker showed a significant higher volume load in a close correlation with the growth hormone treatment (Figure 3). Our approach to overcome loop diuretic resistance with the addition of a thiazide-type diuretic to frusemide to produce diuretic synergy via "sequential nephron blockade" [8] was successful and volume load and NT-BNP decrease (Figures 2 and 3). However, one month later the boy developed renal failure and was listed as high urgency recipient for heart transplantation.

After successful heart transplantation NT-BNP drop down and IGF-1 and IGF-1BP increase to normal values without any growth hormone replacement. The boy showed an impressive catch up growth up to the third percentile $(165 \mathrm{~cm})$ within the next four years (Figure 1).

\section{Discussion and conclusion}

In the first published trial about recombinant human growth hormone treatment for dilated cardiomyopathy in children

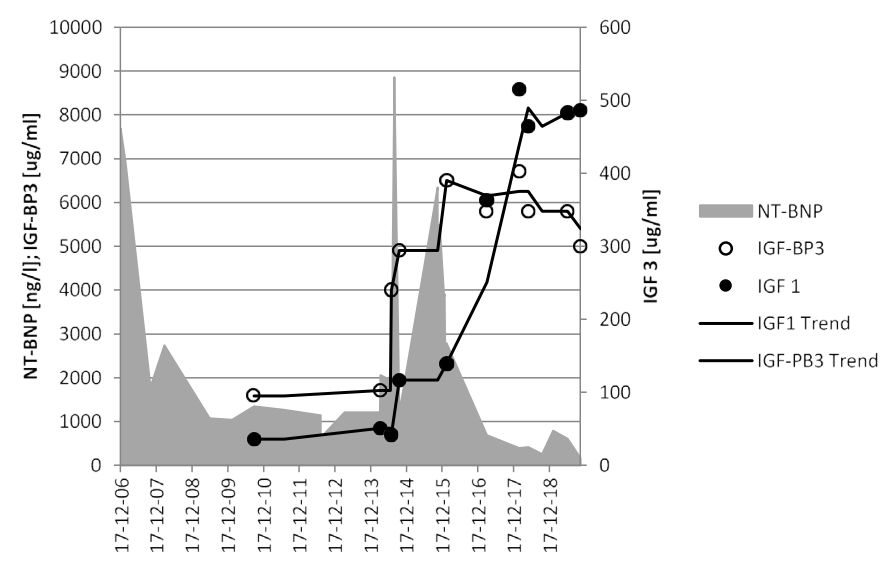

Figure 2. NT- Brain natriuretic peptide (NT-BNP), insulin like growth factor 1 (IGF-1) and insulin like growth factor binding protein (IGF-BP3) of a boy with chronic heart failure after mitral valve replacement at the age of 4 years. Cardiac decompensation at the age of 11 years after starting growth hormone therapy for short stature of cause chronic heart failure due to dilated cardiomyopathy. After cardiac recompensation and renal failure, he needs heart transplantation after one year waiting time. After recovery, spontaneous increase of IGF 1 and IGF-PB3.

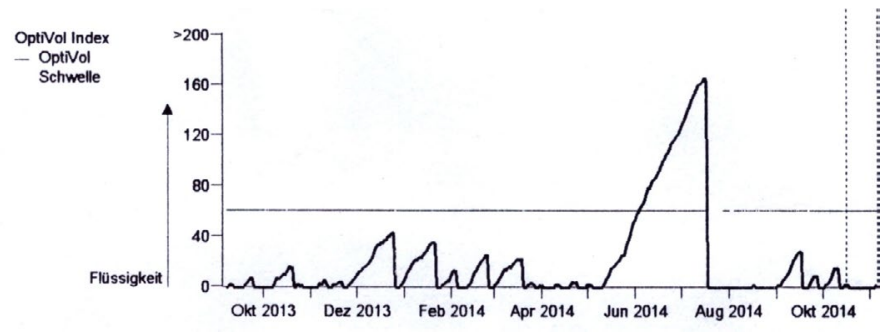

Figure 3. Original reprint of the 11 years old boy with heart failure due dilated cardiomyopathy. Fluid balance was measured by the implanted biventricular pacemaker $\left(\mathrm{OptiVol}{ }^{\mathrm{TM}}\right)$. After introduction of growth hormone therapy in month of May 2014 he developed volume retention treated with addition of thiazides to high dose loop diuretics for cardiac recompensation in July 2014.
McElhinney et al. [6] report that two of the eight patients developed progressive heart failure and underwent cardiac transplantation. We now report a third very well documented case of a life-threatening cardiac decompensation in a boy who received a low dose growth hormone treatment for short stature due to chronic severe heart failure. We conclude:

1. Living is more important than growing and growth hormone replacement should not be used in children with heart failure.

2. Whenever there is chance to improve heart failure by cardiac surgery there is a high potential for catch up growth when the epiphyseal clefts are open.

3. Betablockers improve clinical signs of heart failure and reduce neurohormonal activation but are probably not able to prevent the risk of severe short stature due to chronic heart failure.

We proposed a model that explain short stature by autonomic imprinting due to early life stress [9]. Heart failure is one of the main causes of early life stress indicated by highly elevated norepinephrine levels [10] and reduced heart rate variability [11]. Early cardiac surgery of congenital heart defects [4] and preoperative treatment of heart failure with propranolol [12] are the therapies of choice to prevent early life stress in infants with heart failure due to congenital heart defects. There is a growing evidence that early life stress has an impact on both, final height and a worse neurodevelopment outcome after surgery of congenital heart defects [5]. Early life stress seems to be related to hippocampal growth delay [13] the common pathway of critical illness in infancy.

If heart failure is not preventable by cardiac surgery - as in our case with dilated cardiomyopathy - we may protect the heart against the deleterious effect of stress with a betablocker and improve the clinical state but we are not able to improve the disturbed hypothalamus hypophysis axis that leads to short stature. Probably low IGF-1 levels in children with heart failure indicates the disturbed hypothalamic regulation and growth hormone replacement may improve growth. However, growth hormone therapy leads to an increment in sympathetic activity as shown by Tanriverdi et al. [14] that is no problem for the healthy hearts but a big problem for patients with left ventricular dysfunction.

\section{References}

1. Le Roy C, Larios G, Claveria C, Springmuller D (2019) Short stature among children undergoing cardiac surgery for congenital heart defects. Arch Argent Pediatr 117: e211-e217. [Crossref]

2. Peng J, Fu J, Deng SZ, Wang RG, Liu L, et al. (2013) Changes in serum insulin-like growth factor-1 and insulin-like growth factor-binding protein-3, and their significance in children with left-to-right shunt congenital heart disease associated with heart failure. Zhongguo Dang Dai Er Ke Za Zhi 15: 277-280. [Crossref]

3. Surmeli-Onay O, Cindik N, Kinik ST, Ozkan S, Bayraktar N, et al. (2011) The effect of corrective surgery on serum IGF-1, IGFBP-3 levels and growth in children with congenital heart disease. J Pediatr Endocrinol Metab 24: 483-487. [Crossref]

4. Soliman AT, Elawwa A, Khella A, Saeed S, Yassin H (2012) Linear growth in relation to the circulating concentration of insulin-like growth factor-I in young children with acyanotic congenital heart disease with left to right shunts before versus after surgical intervention. Indian J Endocrinol Metab 16: 791-795. [Crossref]

5. Ravishankar C, Zak V, Williams IA, Bellinger DC, Gaynor JW, et al. (2013) Association of impaired linear growth and worse neurodevelopmental outcome in infants with single ventricle physiology: a report from the pediatric heart network infant single ventricle trial. J Pediatr 162: 250-256. [Crossref]

6. McElhinney DB, Colan SD, Moran AM, Wypij D, Lin M, et al. (2004) Recombinan human growth hormone treatment for dilated cardiomyopathy in children. Pediatrics 114: e452-e458. [Crossref] 
Buchhorn R (2019) Short stature in severe paediatric heart failure: The deleterious role of growth hormone replacement

7. Cittadini A, D'Assante R (2018) Growth hormone in heart failure revisited: An old story retold. Monaldi archives for chest disease. Archivio Monaldi per le malattie del torace 88: 989.

8. Jentzer JC, DeWald TA, Hernandez AF (2010) Combination of loop diuretics with thiazide-type diuretics in heart failure. J Am Coll Cardiol 56: 1527-1534. [Crossref]

9. Buchhorn R, Meint S, Willaschek C (2016) The Impact of Early Life Stress on Growth and Cardiovascular Risk: A Possible Example for Autonomic Imprinting? PLOS ONE 11: e0166447. [Crossref]

10. Ross RD, Daniels SR, Schwartz DC, Hannon DW, Shukla R, et al. (1987) Plasma norepinephrine levels in infants and children with congestive heart failure. $\mathrm{Am} J$ Cardiol 59: 911-914. [Crossref]
11. Buchhorn R, Hammersen A, Bartmus D, Bursch J (2001) The pathogenesis of heart failure in infants with congenital heart disease. Cardiol Young 11: 498-504. [Crossref]

12. Buchhorn R, Hulpke-Wette M, Hilgers R, Bartmus D, Wessel A, et al. (2001) Propranolol treatment of congestive heart failure in infants with congenital heart disease: The CHF-PRO-INFANT Trial. Congestive heart failure in infants treated with propanol. Int J Cardiol 79: 167-173. [Crossref]

13. Schiller R, IJsselstijn H, Hoskote A, White T, Verhulst F, et al. (2008) Memory deficits following neonatal critical illness: a common neurodevelopmental pathway. Lancet Child Adoles Health $2:$ 281-289.

14. Tanriverdi F, Eryol NK, Atmaca H, Unluhizarci K, Ozdogru I, et al. (2005) The effects of 12 months of growth hormone replacement therapy on cardiac autonomic tone in adults with growth hormone deficiency. Clin Endocrinol (Oxf) 62: 706-712. [Crossref]

Copyright: (O2019 Buchhorn R. This is an open-access article distributed under the terms of the Creative Commons Attribution License, which permits unrestricted use, distribution, and reproduction in any medium, provided the original author and source are credited. 